\title{
Usulan Formulasi Strategi PT ABC dalam Kompetisi Industri EPC Migas di Indonesia
}

\begin{abstract}
A. Yoshana
Abstrak - Kebutuhan minyak bumi di Indonesia meningkat setiap tahunnya tetapi hal ini tidak seimbang dengan produksi dalam negeri yang terus menurun. Kondisi ini membuat pemerintah berusaha untuk meningkatkan kapasitas produksi minyak bumi di dalam negeri sehingga mendorong aktivitas eksplorasi, pengembangan dan produksi yang didukung oleh kontraktor, konsultan, perusahaan EPC dan penyedia jasa lainnya dalam bidang migas. PT ABC adalah perusahaan yang bergerak dalam bidang distribusi produk dan EPC migas di Indonesia sejak tahun 1986. Sayangnya peluang bisnis yang berkembang belum dapat dimanfaatkan. Pada tahun 2013 sampai tahun 2014 pendapatannya menurun padahal mempunyai sumber daya dan kemampuan yang mendukung kompetensi intinya sebagai perusahaan EPC yang didukung oleh produk yang didistribusikannya. Pada beberapa proses lelang, perusahaan mengalami kekalahan yang diakibatkan oleh harga yang lebih tinggi daripada pesaing. Akar masalah dari isu bisnis adalah perusahaan kurang menyelaraskan strategi perusahaan ke dalam strategi semua unit kerja. Sebagai solusinya ABC membuat formulasi strategi mulai dari strategi korporat, strategi bisnis sampai strategi fungsional. Berdasarkan analisa lingkungan bisnis dan internal perusahaan, saran strategi yang terbaik adalah cost focus untuk melayani pasar yang spesifik (niche market) dengan memanfaatkan kompetensi intinya. Strategi ini dilaksanakan melalui harga lebih murah dengan tetap mempertahankan kualitas.
\end{abstract}

Kata Kunci-EPC, Manajemen Strategi, Strategi Korporat, Strategi Bisnis, Strategi Fungsional

Abstract - The need for petroleum in Indonesia is increasing every year but this is not balanced with domestic production which continues to decline. This condition has made the government try to increase domestic oil production capacity so as to encourage exploration, development and production activities supported by contractors, consultants, EPC companies and other service providers in the oil and gas sector. PT ABC is a company engaged in the distribution of products and EPC oil and gas in Indonesia since 1986. Unfortunately, developing business opportunities cannot be utilized. In 2013 to 2014 its income declined even though it had the resources and capabilities that supported its core competencies as an EPC company supported by the products it distributed. In some tenders, the company suffered a loss caused by higher prices than competitors. The root cause of the business issue is that the company does not harmonize the company's strategy into the strategies of all work units. As a solution ABC formulates strategies ranging from corporate strategies, business strategies to functional strategies. Based on the analysis of the business and internal environment of the company, the best strategy suggestion is cost focus to serve the niche market by utilizing its core competencies. This strategy is implemented through cheaper prices while maintaining quality.

Keywords-EPC, Strategic Management, Corporate Strategy, Business Strategy, Functional Strategies

\section{PENDAHULUAN}

$\mathrm{P}$ $\mathrm{ABC}$ yang kemudian disebut $\mathrm{ABC}$ adalah perusahaan dengan investasi dalam negeri yang didirikan pada tahun 1986 di Jakarta. Pada awal pendirian adalah sebuah toko distribusi di Jakarta dengan bisnis inti distribusi peralatan industri kemudian memiliki konsumen perusahaan migasdi Indonesia. Pada tahun 2000, ABC memperluas bisnis dalam layanan teknis dan konstruksi untuk sektor industri migas. Ruang lingkup bisnisnya adalah industri migas, petrokimia, kimia, kilang, dan energi listrik di Indonesia. Untuk mengidentifikasi masalah yang dihadapi oleh $\mathrm{ABC}$, salah satu indikator yang

Andri Yoshana, Dosen Program Studi Teknik Industri, Universitas Indraprasta PGRI, Jakarta. (andriyoshana@yahoo.co.id) dijadikan acuan adalah jumlah pesanan penjualan (sales order). Pesanan penjualan untuk 2012 hingga 2013, menurun $86 \%$. Pada tahun 2013, ada banyak proyek prospektif yang tidak dilayani atau hilang. Pencapaian terendah berasal dari unit bisnis EPC. Kondisi ini terus berlanjut hingga kuartal pertama tahun 2014.

Terkait penurunan kinerja perusahaan EPC sesuai hasil penelitian yang dipublikasikan tahun 2017 [1] menyatakan bahwa perusahaan EPC cenderung memperhatikan lingkungan internal dibandingkan lingkungan eksternal. Berdasarkan masalah turunnya penjualan yang diidentifikasi di atas, pertanyaan penelitian adalah sebagai berikut:

1. Mengapa kinerja penjualan $\mathrm{ABC}$ menurun? 
2. Apa peluang dan ancaman yang dihadapi oleh $\mathrm{ABC}$ berdasarkan lingkungan eksternal?

3. Apa kekuatan dan kelemahan $\mathrm{ABC}$ berdasarkan analisis kondisi internal?

4. Apa strategi terbaik untuk $\mathrm{ABC}$ untuk meningkatkan kinerja penjualan?

5. Bagaimana strategi diimplemensikan?

\section{METODE DAN PROSEDUR}

Penelitian ini dilakukan dengan studi literatur dan wawancara. Studi literatur dilakukan dengan menggunakan referensi strategi bisnis, pemasaran, manajemen operasi dan media yang diberikan oleh perusahaan seperti dokumentasi sistem manajemen terintegrasi dan laporan kinerja perusahaan. Wawancara dilakukan sebagai informasi tambahan dalam eksplorasi masalah bisnis dan solusi. Sumber daya untuk wawancara adalah Jajaran direksi atau Board of Director, perwakilan manajemen, kepala departemen dan kepala bagian. Penulis mendapatkan data primer dan sekunder. Data primer diperoleh melalui wawancara dan observasi perusahaan. Data sekunder diperoleh melalui pengumpulan laporan kinerja $\mathrm{ABC}$ dan studi teoritis. Tahapan kerangka kerja digambarkan sesuai gambar 1 dengan penjelasan kerangka konseptual sebagai berikut:

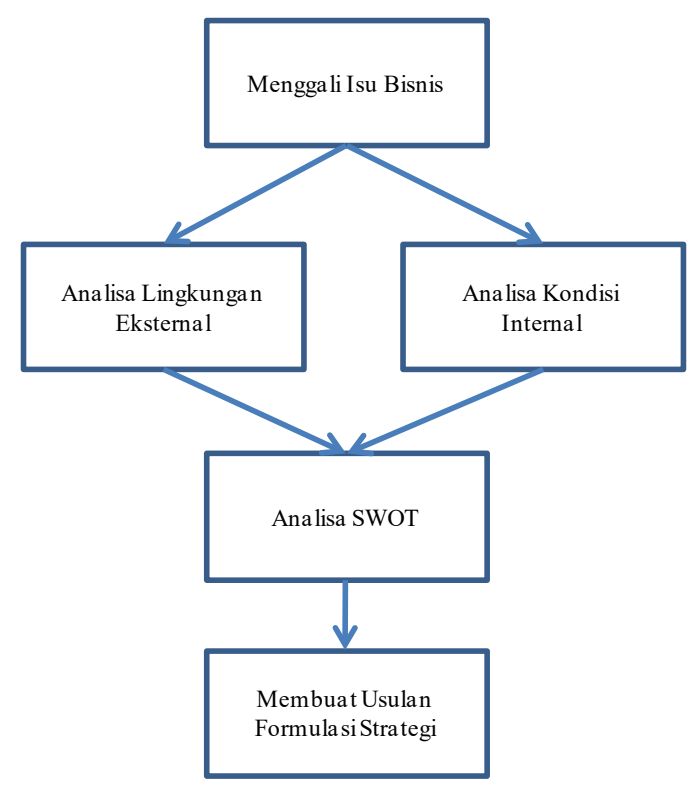

Gambar 1. Kerangka Konseptual

1. Menggali isu bisnis: Mencari akar penyebab terjadinya penurunan penjualan $\mathrm{ABC}$

2. Membuat analisa lingkungan eksternal: Membuat analisa berdasarkan politik, ekonomi, sosial, teknologi, environment dan legal (PESTEL), struktur industri, competitive forces, dan grup strategis.

3. Membuat analisa kondisi internal: Membuat analisa berdasarkan sumber daya, kompetensi inti, VRIO, Value Chain Analysis dan Bench marking.

4. Membuat analisa SWOT : Analisis SWOT (Strengths - Weaknesses - Opportunities-Threats) digunakan sebagai alat untuk membuat analisis situasi bisnis berdasarkan lingkungan eksternal dan kondisi internal

5. Menbuat usulan formulasi strategi:Sebagai solusi bisnis berdasarkan analisa SWOT hasilnya dipresentasikan dalam bentuk Strategi Berlian (Diamond Strategy) yang merangkum strategi korporat $\mathrm{ABC}$.

\section{HASIL DAN PEMBAHASAN}

1. Menggali Isu Bisnis

Penyebab terjadinya penurunan penjualan yang terus menurun adalah $\mathrm{ABC}$ tidak memiliki keselarasan implementasi strategi. Ada proses perencanaan strategi perusahaan tetapi tidak semua manajer dan karyawan memahami kontribusi mereka untuk mendukung kinerja perusahaan sesuai analisis internal dan eksternal. Hal ini membuat ABC memiliki keunggulan kompetitif yang rendah dalam persaingan.

2. Analisa Lingkungan Eksternal dan Kondisi Internal

Analisa eksternal dengan melakukan analisa politik, ekonomi, sosial, teknologi, environment dan legal (PESTEL), struktur industri, competitive forces, dan grup strategis di Indonesia yang mempengaruhi $\mathrm{ABC}$ dan hasilnya dimasukkan langsung ke analisa SWOT. Analisa internal dengan melakukan analisa sumber daya baik manusia, produk, mesin dan peralatan pendukung, kompetensi inti, analisa VRIO untuk mengetahui keunggulan kompetitif dan tingkat kesulitan ditiru pesaing, Value Chain Analysis dan Bench marking dengan perusahaan sejenis.

\section{Analisa $S W O T$}

a. Peluang (Opportunities):

1) Kawasan perdagangan bebas ASEAN (AFTA). Perusahaan bisa mendapatkan harga barang yang lebih murah dari negara anggota AFTA. 
2) Pertumbuhan ekonomi Indonesia yang menjadikan bisnis industri migas masih menguntungkan.

3) Implementasi good governance Indonesia yang membuat proses lelang lebih transparan.

4) Persyaratan konten lokal (TKDN) sebagai keuntungan bagi perusahaan lokal.

b. Ancaman (Threats)

1) Stabilitas politik seperti dampak pada pemilihan presiden

2) Menangani komunitas lokal di wilayah kerja proyek

3) Rekayasa dan teknologi (perangkat keras dan perangkat lunak) kemampuan pesaing meningkat

4) Daya tawar yang tinggi dari pemasok karena kelangkaan dan keunikan dalam produk atau jasa

5) Daya tawar yang tinggi dari pembeli dengan kekuatan negosiasi yang kuat.

6) Persaingan yang tinggi di antara pesaing yang ada dalam kompetisi monopolistik.

c. Kekuatan (Strength)

1) Ruang lingkup bisnis $\mathrm{ABC}$ saling mendukung satu sama lain; EPC didukung oleh distribusi produk sebagai kompetensi inti $\mathrm{ABC}$.

2) Hubungan yang baik dengan pemasok atau pesaing untuk berkolaborasi

3) Kegiatan yang ramping (leanness) dan lincah

4) Kekuatan pengendalian internal

5) Efisiensi proses logistik

d. Kelemahan

1) Tidak mempunyai indikator sinyal peringatan dini berdasarkan lingkungan eksternal seperti kondisi politik yang tidak stabil

2) Kemampuan teknik untuk mendukung penjualan dan proses operasi

3) Kontrol outsourcing

4) Kontrol kualitas dalam logistik dan operasi

5) Hubungan pelanggan terutama untuk menjaga loyalitas pelanggan saat ini

6) Tindakan korektif dan pencegahan yang disebabkan oleh kurangnya transfer pengetahuan.

\section{Usulan Formulasi Strategi}

a. Strategi Korporat

Sebagai solusi bisnis berdasarkan analisa SWOT, hasilnya dipresentasikan dalam bentuk strategi berlian (diamond strategy) yang merangkum strategi korporat $\mathrm{ABC}$ yang dibagi menjadi lima elemen sesuai gambar 2. Unsurunsurnya adalah arena, kendaraan(vehicle), pembeda (differentiator), pementasan atau tahapan (staging) dan logika ekonomi (economy logic).

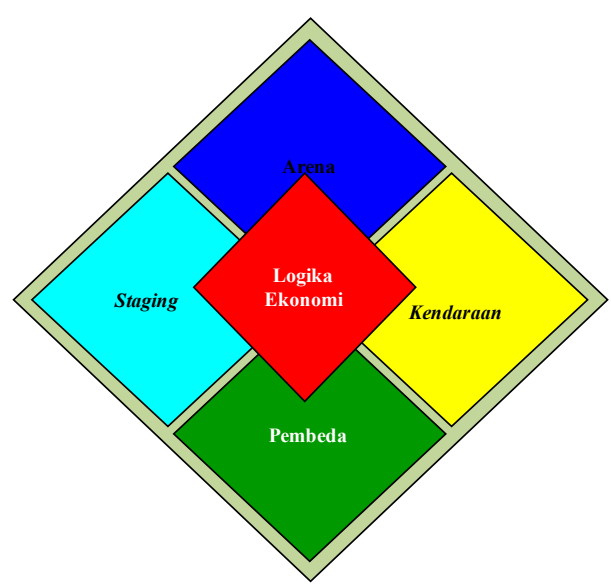

Gambar 2. Strategi Berlian

Arena menentukan dimana atau di arena apa bisnis perusahaan akan aktif. Untuk memformulasikan arena, $\mathrm{ABC}$ menentukan kategori produk, segmen pasar, area geografis dan tahap penciptaan nilai sebagai berikut:

1) Menyediakan Layanan EPC dengan dukungan distribusi produk yang dimiliki.

2) Mempunyai pelanggan utama perusahaan Kontraktor Kontrak Kerja Sama (KKKS) seperti Chevron Pacific Indonesia, Petrochina, Pertamina, Talisman

3) Perusahaan menargetkan semua wilayah kerja migas di Indonesia sebagai ruang lingkup geografisnya.

Kendaraan adalah keputusan bagaimana perushaan mencapai tujuan di arena tertentu atau tahap penciptaan nilai sebagai berikut:

1) $\mathrm{ABC}$ mengendalikan pembelian

2) Mengoptimalkan dukungan distribusi produk

3) Manajemen proyek didukung oleh supplier terutama perusahaan rekayasa dan konstruksi sebagai bentuk integrasi vertikal 
dan membuat aliansi strategis di bidang teknik dan konstruksi.

Pembeda adalah strategi bagaimana $\mathrm{ABC}$ akan menang di pasar yang dilayani melalui strategi bisnis fokus biaya (cost focus) untuk memberikan harga lebih rendah dari pesaing dengan kualitas yang minimal sama

Staging menentukan kecepatan ekspansi dan urutan inisiatif. Berdasarkan tahap pencocokan di atas, $\mathrm{ABC}$ menerapkan penetrasi pasar untuk pelanggan yang sudah ada dan memperluas bisnis menjadi perusahaan EPC selangkah demi langkah sebagai berikut:

1) Langkah 1. Manajemen Proyek

2) Langkah 2. Pengadaan

3) Langkah 3. Konstruksi

4) Langkah 4. Engineering

Logika Ekonomi menentukan bagaimana keuntungan dihasilkan dan memperoleh pengembalian. ABC menerapkan fokus biaya dan untuk membuatnya tetap menguntungkan, ABC harus meningkatkan skala ekonomis untuk mendapatkan keuntungan.

\section{Strategi Fungsional}

Adalah strategi di bidang fungsional perusahaan untuk mencapai tujuan perusahaan dan bisnis dengan memaksimalkan produktivitas sumber daya. Strategi ini dibuat setelah strategi korporat selesai dibuat atau merupakan turunannya. Strategi bisnis yang dibuat sesuai dengan strategi korporat adalah cost focus yang menjadi acuan strategi fungsionalnya. Strategi fungsional $\mathrm{ABC}$ dibagi menjadi tujuh fungsi sebagai berikut: (a) Logistik, (b) Operasi, (c) Pemasaran, Penjualan, dan Layanan, (d) Pengadaan, (e) Pengembangan teknik dan teknologi, (f) Sumber daya manusia, dan (g) Infrastruktur Perusahaan.

a. Logistik

Untuk menurunkan biaya melalui efisiensi aliran produk dengan cara mengimplementasikan pergudangan yang ramping, menggabungkan multi-stop truckload dan routing yang optimal, Mengoptimalkan fasilitas AFTA untuk bahan impor

b. Operasi

Melakukan inovasi pada produk dan perbaikan pada proses bisnisnya.

c. Pemasaran, Penjualan dan Layanan

Dalam rangka meningkatkan penetrasi pasar $\mathrm{ABC}$ harus meningkatkan promosi dan pendidikan kepada pelanggan melalui bauran komunikasi pemasaran yaitu melalukan direct selling, pelatihan, testimonial, email penawaran, web site, linked in, facebook, pameran dagang atau brosur.

d. Pengadaan

Dalam proses pembelian, biaya proyek EPC terbesar berasal dari peralatan utama. Untuk menurunkan biaya, strateginya adalah sebagai berikut:

1) Berkolaborasi dengan pemasok mulai dari awal proses penawaran.

2) Mencari atau mendapatkan sumber biaya rendah bahan impor dari anggota AFTA jika tidak ada pemasok lokal atau harga lokal tidak kompetitif

3) Memilih pemasok dengan kemampuan untuk menanggapi perubahan dan memiliki efisiensi proses

4) Membeli langsung ke manufaktur tanpa melewati pengecer dan distributor untuk meningkatkan penghematan biaya

5) Melakukan proses outsourcing untuk pengerjaan yang lebih murah oleh pihak luar

6) Meningkatkan konten lokal untuk mendapatkan daya saing dalam proses penawaran

e. Pengembangan teknik dan teknologi

Melakukan analisia nilai (value analysis) dan rekayasa nilai (value engineering) untuk mencapai kinerja yang baik dengan biaya lebih rendah

f. Sumber daya manusia

Mengatur ulang atau menyelaraskan kebutuhan sumber daya manusia dengan pilihan strategis.

g. Infrastruktur Perusahaan.

Memaksimalkan proses analisis data pemasaran berdasarkan permintaan pelanggan. Dalam rekayasa proses, database proyek dapat diproses untuk mendukung proyek.

\section{Implementasi Strategi}

Tahap akhir strategi bisnis adalah implementasi strategi. Untuk mengatur keunggulan kompetitif, 
$\mathrm{ABC}$ harus menerapkan strategi melalui:

a. Desain organisasional agar tetap ramping (leanness), lincah dan biaya bersaing, ABC harus menerapkan struktur organisasi mekanistik.

b. Budaya yang diperlukan untuk strategi fokus biaya adalah:

1) Fokus pada pelanggan dan memberikan "kepuasan pelanggan yang belum pernah terjadi sebelumnya"

2) Perbaikan berkelanjutan

3) Berbagi pengetahuan terkait dengan peningkatan proses bisnis

4) Budaya kerja tim untuk menghilangkan sindrom "bukan pekerjaan saya"

b. Kontrol strategis

1) Mengembangkan penyelarasan strategis untuk menerapkan strategi dalam seluruh fungsi atau proses dengan alat seperti Balanced Scorecard.

2) Mengembangkan indikator kinerja utama

3) Mengembangkan sistem penghargaan

\section{IV.SIMPULAN}

Untuk mendapatkan dan mempertahankan keunggulan kompetitif, $\mathrm{ABC}$ harus menyelaraskan strategi bisnisnya dengan lingkungan bisnis yang dinamis. Sumber daya, kemampuan, dan kompetensi $\mathrm{ABC}$ harus disesuaikan dengan perubahan ini. Strategi tingkat perusahaan, strategi tingkat bisnis, dan strategi tingkat fungsional diredefinisikan berdasarkan misi, visi, tujuan, analisis eksternal dan analisis internal sebagai tahap input dalam perumusan strategis.

Beberapa alternatif dihasilkan dalam tahap pencocokan berdasarkan matrik SWOT. Hasil seleksi dalam tahap keputusan adalah $\mathrm{ABC}$ harus menerapkan strategi penetrasi pasar untuk layanan yang ada di pasar yang ada karena strategi ini lebih menarik untuk menggunakan kekuatan, memperbaiki kelemahan internal, memanfaatkan peluang dan menghindari dampak dari ancaman eksternal. Strategi fungsional $\mathrm{ABC}$ adalah fokus biaya dalam lingkup persaingan target sempit dan keunggulan kompetitif biaya yang lebih rendah sejalan dengan persyaratan pelanggan dalam pengadaan jasa migas bahwa yang menang adalah penawar terendah setelah lulus administrasi dan kualifikasi teknis. Strategi fungsional ini menggabungkan konsep dari manajemen strategis, pemasaran layanan, dan manajemen operasi.Untuk merealisasikan strategi atau mengubah perumusan strategi ke dalam tindakan.

Selanjutnya $\mathrm{ABC}$ perlu membuat implementasi strategi yang terkait dengan desain organisasi, budaya dan kontrol yang terkait dengan organisasi fokus biaya. Struktur organisasi mekanistik cocok dengan strategi fokus biaya. Budaya yang terkait dengan pelanggan dan fokus biaya mendukung strategi. Akhirnya untuk meningkatkan kurangnya keselarasan strategis, $\mathrm{ABC}$ harus menerapkan alat penyelarasan seperti Balanced Scorecard. Tantangan proses pengendalian implementasi strategi adalah untuk mencapai keseimbangan yang tepat dari kontrol keuangan dan strategis untuk meningkatkan kinerja perusahaan. Untuk merealisasikan strategi atau mengubah perumusan strategi ke dalam tindakan.

\section{UCAPAN TERIMA KASIH}

Penulis mengucapkan terima kasih kepada perusahaan $\mathrm{PT} \mathrm{ABC}$ yang telah memberikan kesempatan dan dukungan untuk melakukan penelitian ini serta kepala program studi, sekretaris program studi, team editor JOTI yang telah mendukung perbaikan jurnal ini dan dosen Teknik Industri, Universitas Indraprasta PGRI Jakarta yang selalu memberikan motivasi dan bimbingannya.

\section{REFERENCES}

[1] E. Suhendar, A. Endih, D. Indrajaya, (2017). Analisis Faktor Internal dan Eksternal Perusahaan EPC Migas di Indonesia dalam Seminar Nasional Riset dan Inovasi Teknologi (pp. 135-142)

[2] F. David, (2011). Strategic Management: Concepts and Cases (13th ed.), New Jersey: Prentice Hall.

[3] R. Ireland, R. Hoskisson, dan M. Hitt, (2013). The Management of Strategy, (10th ed.), Mason, Ohio: South-Western Cengage.

[4] F. Jacobs, dan R. Chase, (2011). Operations and Supply Management (13th ed.), New York, NY: McGraw-Hill/Irwin.

[5] C. Lovelock, S. Vandermerwe, B. Lewis, dan S. Fernie, (2011). Services Marketing (2nd ed.), 
Edinburgh: Edinburgh Business School HeriotWatt University.

[6] F. Rothaermel, (2013).Strategic Management: Concepts (1st ed.), New York: McGraw-Hill/ Irwin.

[7] T. Wheelen, dan J. Hunger, (2012). Strategic Management and Business policy: Toward Global Sustainability (13th ed.), New Jersey: Prentice Hall.

[8] IMF. (2014).Regional Economic Outlook - Asia and Pacific, World Economic and Financial Survey, n.p, n.pag.

[9] PWC. (2012).Staring Down The Barrel, An Investor Survey of The Indonesian Oil and Gas Industry, May: 20-22. 